\title{
The backup recovery strategy selection to maintain the business continuity plan
}

\author{
Faisal $^{1, *}$ \\ ${ }^{1}$ Industry Creative and Telematics Faculty, Trilogy University, Jl. TMP Kalibata Jakarta 12760, Indonesia
}

\begin{abstract}
Indonesia faces the risks of volcanic eruptions, earthquakes, floods and tsunamis, which destruct its land areas and also result in damage to client and server computer systems. The demand for the information technology availability and performance becomes high. Disaster recovery plan is designed to ensure the vital business processes continuation in the event a disaster occurs. The problem is how to make the best way in selecting backup recovery strategy based on the benefits to the cost ratio so as to minimize the business losses that will be caused by the failure of an application system. This research aims to make decisions that can help make certain parties take the best decision in choosing the backup recovery strategy for a business continuity plan in the Trilogy University. The research method used is the multi-criteria decision-making and analytical hierarchy process by using the expert choice software. From the research results can be concluded that the first order in backup strategy is hot standby option $59,4 \%$, followed by cold standby option $23,3 \%$, then the choice of warm standby option $17,4 \%$. The data inconsistency rate is 0.02 , smaller than 0.1 as the maximum value of inconsistency ratio.
\end{abstract}

\section{Introduction}

Located in the Pacific ring of fire, Indonesia faces volcanic eruptions, earthquakes, floods, tsunamis, which destruct its land (including many infrastructures that consequence in economic losses). There are some notable disaster events: volcanic eruption in Central Java in November 3, 2010; floods and landslides in many parts of Indonesia; and an earthquake in the Indian Ocean followed by a tsunami, killing 167,000 people in Indonesia (mainly in Aceh) in 2004 [1].

Those disasters have tremendous strength and scale of damage that result in unplanned power outages and damage to client's computer systems. Damage can also occur due to virus attacks on information technology from the data exchange through the internet connected to databases worldwide, which also resulted in economic losses. Konsa and Jeeser (2017) stated that although natural disasters and different types of emergencies are relatively uncommon, they can nevertheless cause extensive damage, the consequences of which are usually very expensive to recover from [2]. Otair, Mohammed and Aiman Al-Refaei (2015) suggested that although cybercrimes are radically different from other kinds of crimes, the damage caused by cybercrimes cannot be separated from the damage that results from other kinds of crimes, and so it should not be underestimated [3].

Those conditions should have alerted the information technology management to immediately implement a disaster recovery strategy. A disaster recovery plan can be used as a guide if the company's business is paralyzed, unable to operate properly when a disaster occurs. Bryan C. Martin (2002) suggests that this disaster recovery plan is designed to ensure the important business processes sustainability when a disaster occurs [4]. This disaster recovery plan will provide an effective solution that can be used to restore all important business processes within the required timeframe of vital records stored off-site.

The Trilogy University has an academic information system that is one of the important assets that includes student data, lecturer data, and other academic data. There are also other very important complex data transactions such as financial data as well as human resource data. The disaster recovery plan implementation at Trilogy University will be used as a reference in measuring the implementation of a viable disaster recovery plan on critical business support applications so that business operations can continue to run normally in the event of a disaster or system failure.

With the increasing academic process in the University Trilogy, the demand for the information technology availability and performance becomes high. The information technology components that do not work will cause huge economic losses because the system component has become an integral part of the company's operations. With increasing levels of dependence on information technology and to avoid the risk of disruption in operational performance, it requires the good and optimum disaster recovery plan implementation. The implementation is supported by reliable technology so that business processes can continue to run because the necessary data can be stored.

Based on the above backgrounds, the question is how to choose the best option for selecting backup recovery

Corresponding author: faisalpiliang@trilogi.ac.id 
strategy at Trilogy University. The selection criterion is based on the benefits ratio to the cost ratio, to minimize the business losses that will be caused by the failure or malfunction of an application system. It can also be used for the business continuity plan. The method used in this research is the multi-criteria decision making and analytical hierarchy process using the expert choice software. The research aims to make decisions that can help the university's stakeholder to make the best decision in choosing the backup recovery strategy for a business continuity plan at Trilogy University.

\section{Materials and method}

The disaster recovery plan is defined as an anticipatory planning process for unpredictable events and no organization knows when it occurs and its effect on the continuity of existing business processes [5]. The disaster recovery plan is also defined as a planning that focuses on information systems to restore operability target system, applications, and computer facilities at alternative locations in emergency conditions [6]. The causes of system failure include flood, earthquake, fire, tsunami, terrorist acts, sabotage acts, the act of war, electrical power failures, uninterruptible power supply failure. Those will cause the malfunctioning system without being predictable.

The location of diversion during a disaster should also be considered [6]:

a. Hot Standby is a fully prepared environment.

b. Warm Standby is a ready-made environment. It has almost all recovery needs except hardware.

c. Cold Standby is a ready-to-go location with only supporting infrastructures

Analytical hierarchy process was developed by Dr. Thomas L. Saaty of the Business Wharton School in the 1970s to organize information and judgment in choosing the most preferred alternative [7-10]. The working principle of the analytical hierarchy process is criteria and alternative assessments are assessed through pairwise comparisons. According to Saaty (1983) for a variety of issues, the scale 1 to 9 is the best scale in expressing opinions [7], as shown in Table 1.

Table 1. Comparison scale Saaty [10], [8]

\begin{tabular}{|c|l|}
\hline Grade & \multicolumn{1}{|c|}{ Explanation } \\
\hline 1 & $\begin{array}{l}\text { Criterion / Alternative A is equally important } \\
\text { with criterion/alternative B }\end{array}$ \\
\hline 3 & A is slightly more important than B \\
\hline 5 & A is clearly more important than B \\
\hline 7 & A is clearly more important than B \\
\hline 9 & A is absolutely more important than B \\
\hline $2,4,6,8$ & When in doubt between two adjacent grades \\
\hline
\end{tabular}

The value of comparison A with B is 1 (one) divided by the value of comparison $\mathrm{B}$ with $\mathrm{A}$.

The following are the review of previous related studies related to this research. Konsa, 2017, using Analytical Hierarchy Process approach in determining the risk of disaster rating in the museum [2]. Soedarmaji, 2000 conducted a study of research on the planning of disaster recovery centre due to system failure in the capital market of PT. Jakarta Stock Exchange [11]. Cahyadi, 2006, discusses the business continuity plan with aviation industry PT. Garuda Indonesia [12]. Wulandari, 2008, review disaster recovery plan with the Analytic Hierarchy Process approach at PT. Bank Mega Tbk [9]. The research framework can be seen in Table 2.

Table 2. The research framework

\section{The Framework Model}

Feedback: Analysis, surveys, interviews, and discussions with expert respondents in the University Trilogy;

Objectives: Obtained research thinking;

Method: Focus group discussion with expert respondents;

Output: Review the backup process selection.

Feedback: Data from distributed questionnaires to expert respondents;

Objectives: Define the benefit criteria;

Method: Focus group discussion with expert respondents and Cochran Q test approach;

Output: Risk; Reliability and Maintenance; Trust.

Feedback: Data from distributed questionnaires to expert respondents;

Objectives: Define cost criteria;

Method: Focus group discussion with expert respondents and Cochran Q test approach;

Output: Disaster Recovery Centre; Infrastructure and Training; Backup; Testing.

Feedback: Data from distributed questionnaires to expert respondents;

Objective: Define Risk sub-criteria;

Method: Focus group discussion with expert respondents and Cochran Q test approach;

Output: Hardware; Software; Infrastructure and Procedure; Backup; Test.

Feedback: Data from distributed questionnaires to expert respondents;

Objective: Define Reliability and Maintenance sub-criteria;

Method: Focus group discussion with expert respondents and Cochran Q test approach;

Output: Hardware; Software; Infrastructure; Backup.

Feedback: Data from distributed questionnaires to expert respondents;

Objective Define benefit alternatives;

Method: Focus group discussion with expert respondents and Cochran Q test approach;

Output: Hot Standby; Warm Standby; Cold Standby.

Feedback: Data from distributed questionnaires to expert respondents;

Objectives: Define cost alternatives;

Method: Focus group discussion with expert respondents and Cochran Q test approach;

Output: Hot Standby; Warm Standby; Cold Standby.

Feedback: Data from paired comparison questionnaires from each criterion, sub-criteria, and alternatives in terms of benefits and cost side;

Objective: To provide recommendations for decision-makers on alternatives from the results of the research;

Method: Focus group discussion and expert choice implementation;

Output: The Backup Recovery Strategy Selection for the Business Continuity Plan.

The above-mentioned framework illustrates the research study that begins with literature studies, company surveys, interviews and discussions with expert 
respondents using the focus group discussion method. Data and information were collected from expert respondents using interview and observation techniques at Trilogy University. Then it proceed to determine the attribute criteria, sub-criteria, and alternatives from the benefit ratio and the cost ratio that is distributed to the respondent's experts using the focus group discussion method and the Cochran Q test.

Terms used in this research are defined as follow. Risk identification is the process of identifying and determining possible tangible and intangible risks. Performance and reliability of the system are as the performance and reliability of the system maintained. Maintenance and system changes are that during maintenance activities and system changes will not affect business processes. Customers trust is the customers' trust in the company can remain well established because it already has disaster management procedures.

In order to avoid inconsistencies in the model, focus group discussion with expert respondents to determine the stages of making a valid model with elements that significantly affect the model. The results obtained from the focus group discussion questionnaire are criteria, sub-criteria, and significant alternatives on the benefits ratio and on the cost ratio. This method uses an iterative approach in which the improper attributes through the analysis process are discarded so that the attributes that are left are really the attributes that are important to be researched.

This research uses a descriptive-analytic method by presenting the summary of interviews and survey results in the form of questionnaires. The questionnaire was given to several respondents who acted as experts, they are one head of information technology division, four staff of information technology staff, one dean of the faculty of creative industries and telematics, one head of information systems study program, and four lecturers of information system courses at the Trilogy University where the research was conducted. The research also used the multi-criteria decision making and analytical hierarchy process method using expert choice software computer.

Furthermore, a secondary data search was conducted through various media, such as internet, literature book and journals and articles to obtain accurate information about the research. In addition, the identification of the system by considering the variables supporting the research by conducting interviews and giving questionnaires to experts. This is an important step because the model must be accurate and accountable.

The next strategic step that should be done based on the results of interviews with the respondents expert on the data processed by using an analytical hierarchy of the process. Decisions should be immediately followed up in the form of action or can also be reviewed if the decision was obtained new information that can affect the results to reduce uncertainty, and then the new decision will be obtained. The following is a table of benefits and cost hierarchy diagrams.
Table 3. The benefit hierarchy diagram

\begin{tabular}{|l|c|c|c|}
\hline AIM & \multicolumn{3}{|c|}{ Backup Recovery } \\
\hline Focus & \multicolumn{2}{|c|}{ Benefit } \\
\hline \multirow{4}{*}{ Criteria } & Risk & $\begin{array}{c}\text { Reliability and } \\
\text { Maintenance }\end{array}$ & \\
& Hardware & Hardware & \multirow{2}{*}{ Trust } \\
\cline { 2 - 3 } & Software & Software & \\
\cline { 2 - 3 } & $\begin{array}{c}\text { Infrastructure } \\
\text { and Procedure }\end{array}$ & Infrastructure & \\
\cline { 2 - 3 } & Backup & Backup & \\
\cline { 2 - 3 } & Testing & Hot standby & $\begin{array}{c}\text { Hot standby } \\
\text { Warm standby } \\
\text { Cold standby }\end{array}$ \\
\hline \multirow{3}{*}{ Alternative } & $\begin{array}{c}\text { Hot standby } \\
\text { Warm standby } \\
\text { Cold standby }\end{array}$ & $\begin{array}{c}\text { Warm standby } \\
\text { Cold standby }\end{array}$ & $\begin{array}{c}\text { Cold stand } \\
\text { Coln }\end{array}$ \\
\hline
\end{tabular}

Table 4. The cost hierarchy diagram

\begin{tabular}{|l|c|c|c|c|}
\hline AIM & \multicolumn{4}{|c|}{ Backup Recovery } \\
\hline Focus & \multicolumn{3}{|c|}{ Cost } \\
\hline Criteria & $\begin{array}{c}\text { Disaster } \\
\text { Recovery } \\
\text { Center }\end{array}$ & $\begin{array}{c}\text { Infrastructure } \\
\text { and Training }\end{array}$ & Backup & Testing \\
\hline \multirow{4}{*}{ Alternative } & Hot & Hot standby & Hot & standby \\
& standby & Hot \\
& Warm & Warm & Warm & Warm \\
& standby & standby & standby & Standby \\
& Cold & Cold & Cold \\
& standby & Cold standby & standby \\
\hline
\end{tabular}

According to Marimin, 2005 steps determine the size of weight as follows [8], [10].

$$
\frac{w_{i}}{w_{j}}=a_{i j}
$$

${ }_{\mathrm{i}, \mathrm{j}}=1,2,3, \ldots, \mathrm{n}$

$\mathrm{W}_{\mathrm{i}}=$ weights of inputs in rows

$\mathrm{w}_{\mathrm{j}}=$ weights of input on the lane

$$
w_{i}=a_{i j} \cdot w_{j}
$$

$\mathrm{i}, \mathrm{j}=1,2,3, \ldots, \mathrm{n}$

For common cases have a form:

$$
\begin{gathered}
w_{i}=\frac{1}{n} \sum_{j=i}^{n} a_{i j} w_{j} \\
w_{i=\text { average of }} a_{i 1} \cdot w_{1}, \ldots, a_{i n} \cdot w_{n}
\end{gathered}
$$

If the estimate $a_{i j}$ is good, it will tend to close to $\frac{w_{i}}{w_{j}}$ ratio. If $b$ also changes, then $n$ is converted to $\lambda_{\max }$ so obtained

$$
w_{i}=\frac{1}{\lambda_{\max }} \sum_{j=i}^{n} a_{i j} \cdot w_{j}
$$

$\mathrm{i}, \mathrm{j}=1,2,3, \ldots, \mathrm{n}$

The measure of consistency of answers that will affect the validity as follow:

$$
C I=\frac{\lambda_{\max }-n}{n-1}
$$

The consistency ratio is considered well if $\mathrm{CR} \leq 0.1$. The Consistency Ratio formula as follows:

$$
C R=\frac{C I}{R I}
$$

Consistency ratio is a parameter used to check whether pairwise comparisons have been done 
consequently or not. The random index value released by Oakridge Laboratory, as shown in Table 5.

Table 5. Index random value scale [8], [4]

\begin{tabular}{|cccccccc|}
\hline $\mathbf{N}$ & 1 & 2 & 3 & 4 & 5 & 6 & 7 \\
\hline $\mathbf{R I}$ & 0 & 0 & 0.58 & 0.9 & 1.12 & 1.24 & 1.32 \\
\hline $\mathbf{N}$ & 8 & 9 & 10 & 11 & 12 & 13 & \\
\hline $\mathbf{R I}$ & 1.41 & 1.45 & 1.49 & 1.51 & 1.48 & 1.56 & \\
\hline
\end{tabular}

\section{Results and discussion}

The following are the results from the data processing, analysis, and interpretation for the benefit to cost ratio. Data analysis and interpretation preceded by determining the significant elements at each level of benefit and cost ratio. The first step undertaken in this research is to determine the focus of benefit ratio: backup recovery strategy. The second, to determine the benefit ratio criterion: risk; reliability and maintenance; trust. The third is to determine the sub-criteria of benefit ratio. The fourth is to specify alternatives: hot standby, warm standby, and cold standby.

Further analysis is conducted to answer the research problem that based on the analytical hierarchy process, as shown in the following discussion.

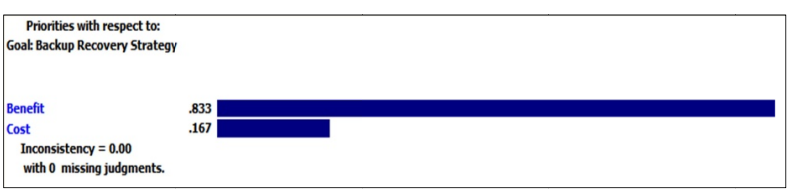

Fig. 1. Research weighting

Figure 1 shows the benefit ratio value weighted is $83.3 \%$ and the cost ratio is $16.7 \%$. The weight of each of the benefit ratios is shown on Figure 2. The weighting are: Risk weight value $65.9 \%$; trust $18.5 \%$; and reliability and maintenance $15.6 \%$.

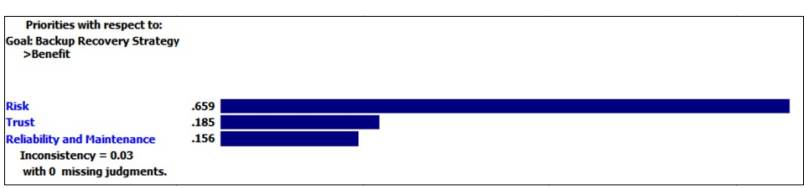

Fig. 2. Weighting the benefit ratio

For the risk criteria, weighs of the criteria are shown in figure 3 .

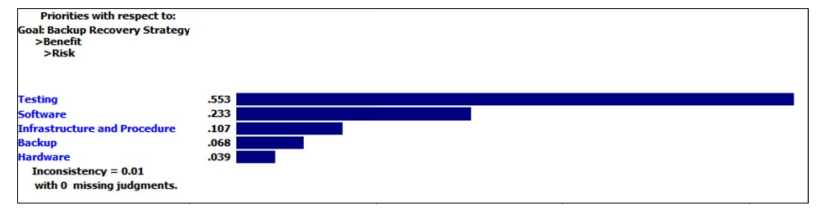

Fig. 3. Weighing the risk

The table above shows that testing weight value is $55.3 \%$; software is $23.3 \%$; infrastructure and procedure is $10.7 \%$; backup is $6.8 \%$; and hardware is $3.9 \%$.

Weight each of the reliability and maintenance criteria is depicted on the following figure.

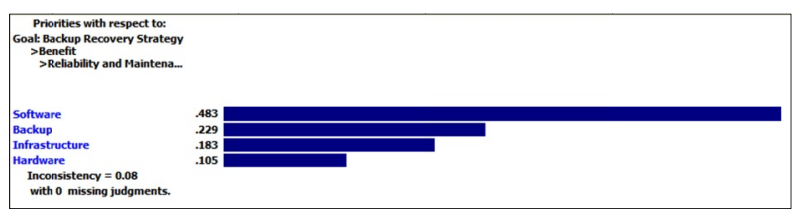

Fig. 4. Weighting the reliability and maintenance

It shows that Software weight value is $48.3 \%$; backup is $22.9 \%$; infrastructure is $18.3 \%$, and hardware is $10.5 \%$. Weight each of trust criteria is shown on figure 5.

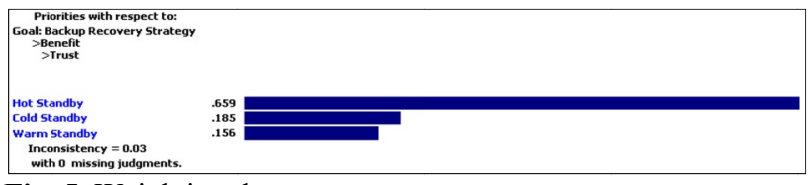

Fig. 5. Weighting the trust

From the table, the value of hot standby weight is $65.9 \%$; cold standby is $18.5 \%$; and a warm standby is $15.6 \%$. The following table 6 shows the weight of each of the cost ratio.

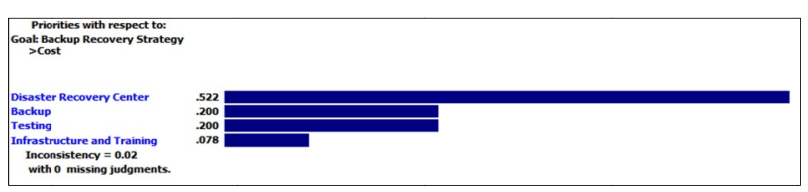

Fig. 6. Weighing the cost ratio

The disaster recovery centre weighted value is $52.2 \%$; backup is $20 \%$; testing is $20 \%$, and infrastructure and training $7.8 \%$. For the global alternate weights that influence the research study, the result is shown on figure 7 .

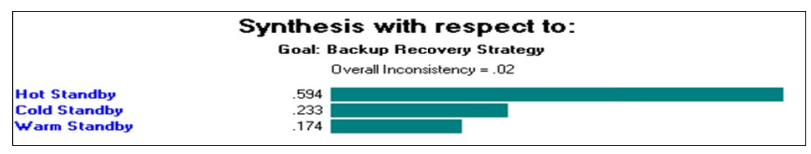

Fig. 7. Global alternative weighting

The value of hot standby weight is $59.4 \%$; cold standby is $23.3 \%$; and a warm standby is $17.4 \%$.

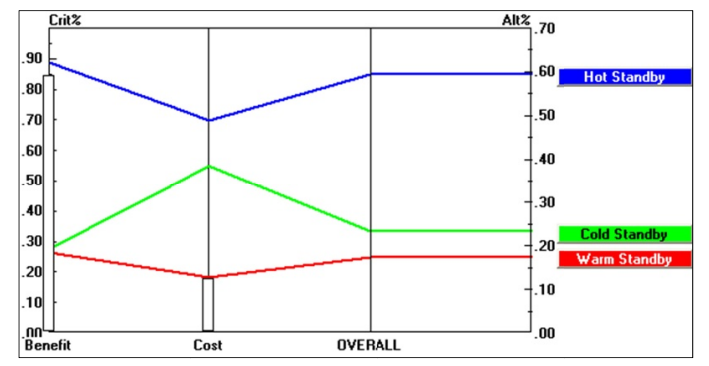

Fig. 8. Global alternative graph

Based on the above graph, it can be concluded that the order of three strategic alternatives is hot standby, cold standby, and warm standby.

Inconsistency ratios of the weighted value of data that have been collected from the expert respondent are 
parameters used to check whether pairwise comparisons have been done consequently or not. The data inconsistency ratios are considered good if the inconsistency ratio (CR) value is $\leq 0.1$, as shown in Table 6.

Table 6. Inconsistency ratio

\begin{tabular}{|c|l|l|}
\hline No & Matrix Comparison of CR Element & Value \\
\hline 1 & Comparison of research & 0.00 \\
\hline 2 & Comparison of the benefit ratio & 0.03 \\
\hline 3 & Comparison of the risk ratio & 0.01 \\
\hline & $\begin{array}{l}\text { Comparison of the reliability and } \\
\text { maintenance }\end{array}$ & 0.00 \\
\hline 5 & Comparison of the trust & 0.03 \\
\hline 6 & Comparison of cost ratio & 0.02 \\
\hline 7 & Globally & 0.02 \\
\hline
\end{tabular}

It can be concluded that the paired pairs given by the expert respondent have inconsistency ratio values smaller than 0.1 as the maximum value of the inconsistency ratio. Thus the results of geometric calculations combined data of expert respondents are quite consistent.

\section{Conclusions}

From the results it can be concluded that the first order in backup recovery strategy is hot standby selection $59.4 \%$; followed by a second order of $23.3 \%$ cold standby, and then the third order is the choice of warm standby $17.4 \%$. The data inconsistency rate is considered good because it is 0.02 , smaller than 0.1 as the maximum value of inconsistency ratio.

This research suggests using hot standby, it can be implemented in Trilogy university, in order to minimize the risks posed by the disaster. It requires commitment and understanding from top management in the implementation of a disaster recovery plan.

We would like to thank the Trilogy University for permitting the use of all available resources. We would like to extend our gratitude to all shareholders who have helped so that this research and article can be completed.

\section{References}

1. Indonesia Investments. Natural Disasters in Indonesia. $\quad \mathrm{https}$ ://www.indonesiainvestments.com/id/bisnis/risiko/bencanaalam/item243. (2017).

2. Konsa, K., and Kaie J. Preparing Museum Disaster Plan: Risk Ranking Through the Analytical Hierarchy Process. IJHCS, 3. (2017).

3. Otair, M., and Aiman Al-Refaei. Cybercrime Fighting Readiness Evaluation Using Analytic Hierarchy Process. The IIER $48^{\text {th }}$ proceedings (2015).

4. Bryan C. Martin., SANS Institute. Disaster Recovery Plan Strategies and Processes, (2002).
5. Carl, N. Disaster Recovery Planning. Final research paper. SIT, (2003).

6. Sharing Vision. Professional Workshop: Step by Step Approach Building Disaster Recovery Strategy and Procedure. Bandung, (2008).

7. Saaty, R.W. The Analytic Hierarchy Process-What it is and how it used. JMM, 9, p. 161-176. (1983).

Saaty, T.L. Decision Making-The Analytic Hierarchal Process, and the Analytic Network Process. JSSSE, 13(1): 35. (2004).

8. Marimin. Techniques and Applications of DecisionMaking Some Criteria. PT. GWI. Jakarta, (2005).

9. Wulandari, D.A. The IT Disaster Recovery Planning Strategy on Core Banking System with Analytic Hierarchy Process Approach: Case Study at PT. Bank Mega Tbk. Thesis at MIK UBL, (2008).

10. Faisal. Disaster Recovery Plan Information Technology Strategy on UICO Core System with Analytical Hierarchy Process Approach. Thesis at MIK STMIK NM, (2010).

11. Soedarmaji, M. Business Planning Based on Disaster Recovery due to Computer System Failure in One of Capital Market Management Company, Case Study of PT. Jakarta Stock Exchange. Thesis at MTI UI, (2000).

12. Cahyadi, E. Review Business Continuity Plan Based on Quantification of Economic Value of Application System on Aviation Industry: Case Study at PT. Garuda Indonesia. Thesis at MTI UI, (2006).

13. Faisal. Decision Support System Image Processing Software Selection with Multi-Criteria Decision Making Method and Analytical Hierarchy Process. The SEMNASTEKNOMEDIA proceeding, 3, (2015). 